\title{
Numerical Study of Unsteady Mass Motion Flow of Power Law Fluid Along a Vertical Plate with the Effect of Viscous Dissipation and Low Magnetic Field
}

\author{
GM Fahad Bin Mostafa*, Md. Rakib Hossain, Md. Abdus Samad \\ Department of Applied Mathematics, University of Dhaka, Dhaka, Bangladesh \\ Email address: \\ fahad education@hotmail.com (GM F. B. Mostafa) \\ ${ }^{*}$ Corresponding author
}

\section{To cite this article:}

GM Fahad Bin Mostafa, Md. Rakib Hossain, Md. Abdus Samad. Numerical Study of Unsteady Mass Motion Flow of Power Law Fluid Along a Vertical Plate with the Effect of Viscous Dissipation and Low Magnetic Field. American Journal of Aerospace Engineering. Vol. 4, No. 4, 2017, pp. 38-53. doi: 10.11648/j.ajae.20170404.11

Received: December 10, 2017; Accepted: January 11, 2018; Published: January 30, 2018

\begin{abstract}
The unsteady laminar boundary layer flow along a vertical stationary plate was investigated by taking into account the viscous dissipation of non- Newtonian fluid in case of free convection particularly. The governing non-linear partial differential equations are transformed into ordinary differential equations using a similarity transformation. Transformed equations have been discretized by finite difference approximation. The effects of viscous dissipation on velocity and temperature profile with unsteady case dimensionless numbers such as, Prandtl number (Pr), Eckert number (Ec), Grashof number (Gr) and magnetic parameter (M) have been depicted. It is observed that the interaction between the viscous heating and the buoyancy force has a significant influence on the results. Small effects have been found for Eckert number $(E c)$. Eventually, skin fiction coefficient $\left(C_{f}\right)$ and heat transfer rate $(\mathrm{Nu})$ are presented in tabular form for engineering studies.
\end{abstract}

Keywords: Unsteady, Non-Newtonian Fluid, Viscous Dissipation, Free Boundary Layer, Skin Fiction, Heat Transfer Rate

\section{Introduction}

From the age of industrial revolution, the study of nonNewtonian fluid flow has become an important matter for the applicants. The effort has arisen largely to optimize industrial system such as, furnaces, ovens and boilers and the interest in our environment and in non-conventional energy sources, e.g. the use of salt-gradient solar ponds for energy collection and storage. In particular, natural convection induced by the simultaneous action of buoyancy forces resulting from thermal diffusion is of considerable interest in nature and in many industrial applications such as, atmospheric science, oceanography, drying processes and solidification of binary alloy. Many manufacturing process involve the cooling of continuous filaments and rate of cooling can be controlled by dewing sheets or filaments in electronically conducting fluid subjected to magnetic field. Sakiadis [1] and [2] was the first who analyzed the boundary layer flow on a continuous moving solid surface in a Newtonian fluid. For various applications in industry, the study of non-Newtonian fluid flow and heat transfer over a stretched surface gets significant attention. These kinds of fluid exhibit non-linear relationship between shear stress and rate of strain such as polymer solutions, molten plastics, paints and food. Raj Gopal et al. [3] investigated flow of viscoelastic fluid over stretching sheet. Dandapat and Gupta [4], further elaborated the problem to study heat transfer. Lots of investigations were done related to stretching sheet problems with linear stretching in different directions for the Newtonian flow in the absence of the magnetic field. These are broadly investigated by Gupta et al. [5], Afzal et al. [6], Banks et al. [7], Grubka et al. [8], Chen et al. [9], M. R. Haque et al. [10]. Nuclear power plants, satellites, space vehicles, and submarines are interest of such engineering areas. In case of high temperature, the interaction of radiation with hydro-magnetic flow has become industrially more noticeable. Takhar et al. [11] studied the radiation effect on MHD free convection flow past a semi-infinite vertical plate using Runge-Kutta Merson Quadrature. Chamkha [12] also studied radiation effects on free convection flow past a semi-infinite vertical plate. Raptis and Perdikis [13] analyzed radiation and free 
convection flow past a moving plate. These investigations are powerful research in the area of fluid mechanics. Now a days various experiments have been done on the magnetohydrodynamic flows and heat transfer because of its important applications in metallurgical industry. In astrophysics and geophysics, it is applied to study the stellar and solar structures, interstellar matter, radio propagation through the ionosphere etc. In engineering it finds its application in MHD pumps, MHD bearings etc. The study of effects of magnetic field on free convection flow is significant in liquid-metals, electrolytes and ionized gases. Kishan and Sashidha Reddy [14] studied the momentum and heat transfer in laminar boundary layer flow of non- Newtonian fluids past a semi-infinite flat plates with the thermal dispersion in the presence of a uniform magnetic field for both the cases of static plate and continuous moving plate. At present time, the radiation effect on MHD flow and heat transfer problems has become more significant industrially. In fluid dynamics, thermal radiation is important for aerospace, chemical, environmental, solar power, and in engineering. Effects of radiation on non-Newtonian fluids have been studied by many researchers Mansour and Gorla [15], Raptis [16], Sajid M and Hayat T [17], Sahoo and Poncet [18]. Free or natural convection is of fundamental interest in many industrial and environmental situations such as air conditioning systems, atmospheric flows, motors, thermal regulation process, cooling of electronic devices, and security of energy systems. Buoyancy is significant in meteorology and in industry. Huge research has been published on free convection flow past a vertical plate. Free convection at a vertical plate with transpiration was investigated by Kolar and Sastri [19]. A numerical study for natural convective cooling of a vertical plate was presented by Camargo [20] with different boundary conditions. Moreover, the study of viscous dissipation has been interestingly increased for decreasing the waste of energy. Numerical study of MHD forced convective flow of a micro polar fluid with various viscosity has been studied by M. A.
Samad et al. [21] The effect of viscous dissipation and pressure stress work on free convection flow along a vertical flat plate has been investigated by Alam et al. [22]. They studied the effect of viscous dissipation in natural convection where he considered viscous dissipation for vertical surfaces subjected to both isothermal and uniform flux surface condition. Later, K. C. Saha et al. [23] investigated the effect of viscous dissipation on MHD free convection flow heat and mass transfer of non-Newtonian fluids along a continuously moving stretching sheet. Recently Fahad B. Mostafa et al. [24] studied combined effect of viscous dissipation and radiation on unsteady free convective non-Newtonian fluid along a continuously moving vertically stretched surface with no-slip phenomena. In this study, an analysis has been carried out to study the effect of unsteady free convection boundary layer flow of non-Newtonian fluid along a vertically stretched surface with viscous dissipation in the presence of very low magnetic field.

\section{Formulation}

The frame of reference is chosen such that plate coincides with $Y$ plane where flow is assumed only for $Y>0$. Here, we will assume free convection with viscous dissipation. Boundary layer has been generalized by the existence of zero velocity at the plate (Figure 3 ). If we choose the frame of reference such a way that stretching surface coincides with the plane $Y$ where flow is assumed only for $Y>0$, the boundary layer is developed beside $X$ - axis. Navier-Stokes equation is taken with the velocity vector $u$, the result can be cast in the form of an equation for the time rate of change of the kinetic energy of the fluid per unit volume. An important term that appears in the result for this quantity is the rate at which the work done against viscous forces is irreversibly converted into internal energy. Suffix of $u$ or $v$ or $T$ represents partial derivative of each component.

Table 1. Chart of Nomenclature.

\begin{tabular}{llll}
\hline Symbol & Meaning & Symbol & Meaning \\
\hline$v$ & Velocity components in the y direction & $P r$ & Prandtl number \\
$U$ & Dimensionless velocity components along x-axis & $\rho$ & Density of fluid \\
$V$ & Dimensionless velocity components along y-axis & $\mu$ & Dynamic viscosity \\
$u$ & Velocity components in the x direction & $\tau$ & Shear stress \\
$M$ & Magnetic parameter & $\delta$ & Thermal boundary layer thickness \\
$C_{f}$ & Coefficient of skin friction & $\Phi$ & Dissipation function \\
$N u$ & Nusselt number & $G r$ & Grashof Number \\
$T$ & Temperature of the field & $\mathrm{v}$ & Kinematic viscosity \\
$\bar{T}$ & Dimensionless temperature & $\alpha$ & Thermal diffusivity \\
$T_{w}$ & Temperature at wall & $\sigma$ & Volumetric coefficient expansion \\
$E c$ & Eckert number & $\sigma_{1}$ & Electric conductivity \\
$K$ & Flow consistency coefficient & $k$ & Stephan-Boltzmann constant \\
$t$ & Time & $R e$ & Thermal conductivity of the fluid \\
\hline & Dimensionless time & & Reynolds number \\
\hline
\end{tabular}


The continuity equation:

$$
u_{x}+v_{y}=0
$$

The momentum equation:

$$
u_{t}+v u_{y}=\frac{k}{\rho} \frac{\partial}{\partial x}\left(\left|u_{y}\right|^{n-1} u_{y}\right)+g \beta\left(T-T_{\infty}\right)-\frac{\sigma B^{2} u}{\rho}
$$

The energy equation:

$$
T_{t}+v T_{y}=\alpha T_{y y}+\frac{k}{\rho C_{p}}\left(\left|u_{y}\right|^{n-1} u_{y}\right)^{2}
$$

Initial conditions:

$$
u=0, T=0 \text { at } t=0
$$

Boundary conditions: $t>0 u=U_{0}, T=T_{w}$, at $y=0$

$$
u=0, T=T_{\infty}, \text { at } y \rightarrow \infty
$$

Here, free stream velocity and temperature are $U_{0}$ and $T_{\infty}$ respectively, $T_{w}$ is the surface temperature. $B$ is the magnetic field, $\mathrm{n}$ is the power law index. $k$ is the thermal conductivity of the fluid, $C_{p}$ is the specific heat at the constant pressure, $\sigma$ is the electric conductivity of the fluid.

\section{Methodology}

In this study, it is important to introduce the dimensionless variable to make the momentum and energy equations dimension free.

$$
\bar{t}=\frac{t u_{0}}{L}, X=\frac{x}{L} Y=\frac{y}{L}, U=\frac{u}{U_{0}}, v=\frac{v}{U_{0}}, \bar{T}=\frac{T-T_{\infty}}{T_{w}-T_{\infty}}
$$

$$
\frac{U_{0}^{2}}{L} \frac{\partial U}{\partial \bar{t}}+\frac{U_{0}^{2} V}{L} \frac{\partial U}{\partial Y}=\frac{k}{\rho} \frac{\partial}{\partial Y}\left[\left(\frac{U_{0}}{L}\right)^{n}\left|\frac{\partial U}{\partial Y}\right|^{n-1} \frac{\partial U}{\partial Y}\right] \frac{\partial Y}{\partial y}+g \beta\left(T_{w}-T_{\infty}\right) \bar{T}-\frac{\sigma B^{2} U_{0} U}{\rho}
$$

Using dimensionless variable, the momentum equation becomes,

$$
\frac{\partial U}{\partial \bar{t}}+V \frac{\partial U}{\partial Y}=\frac{1}{R e} \frac{\partial}{\partial Y}\left[\left|\frac{\partial U}{\partial Y}\right|^{n-1} \frac{\partial U}{\partial Y}\right]+G r \bar{T}-M U
$$

In this case, the dimensionless numbers are local. Thus, these are calculated for this particular fluid problems. Where,

$$
R e=\frac{U^{2-n} L^{n}}{\frac{k}{\rho}} \text { is the Reynolds number, } G r=\frac{g \beta\left(T_{w}-T_{\infty}\right) L}{U_{0}^{2}} \text { is the Grashof number and Magnetic parameter is } M=\frac{\sigma B^{2} L}{\rho U_{0}} .
$$

Similarly, the dimensionless energy equation is,

$$
\frac{\partial \bar{T}}{\partial \bar{t}}+V \frac{\partial \bar{T}}{\partial Y}=\frac{1}{\operatorname{PrRe}} \frac{\partial^{2} \bar{T}}{\partial Y^{2}}+\frac{E c}{R e}\left(\left|\frac{\partial U}{\partial Y}\right|^{n-1} \frac{\partial U}{\partial Y}\right)^{2}
$$

Here, the modified version of dimensionless numbers may appear different in different flows. In this investigation,

Reynold number is $\operatorname{Re}=\frac{U^{2-n} L^{n}}{\frac{k}{\rho}}$, Eckert number is $E c=\frac{U^{n+1}}{C_{p} \Delta T L^{n}}$, Prandlt Number is $\operatorname{Pr}=\frac{k / \rho}{\alpha}\left(\frac{U_{0}}{L}\right)^{n-1}$.

Now, Initial condition: when, $\bar{t}=0$, then $U=0, \bar{T}=0, \frac{\partial U}{\partial Y}=0, \frac{\partial \bar{T}}{\partial Y}=0$.

Boundary condition: when, $\bar{t}>0$, then $U=1, \bar{T}=1$ when $Y=0, U=0, \bar{T}=0$ when $Y \rightarrow \infty$

Let us choose rectangular region of the flow field, the surface is divided into a grid-lines parallel to $X$ and $Y$ axes. Where, $X$ is chosen along the stretching surface of plate and $Y$ is normal to the plate (Figure 3). Suppose, the length of the sheet is $X_{\max }=50$. " $x$ " varies from 0 to 50 and " $y$ " varies for 0 to $Y_{\max }=20$. Step size is $h=\frac{Y_{\max }}{n+1}$.

Here, $\Delta t=\gamma=0.000001$ and for grid spacing for the $\operatorname{space}(p=200)$ and the time $(q=1000000)$ in the $X$ and $Y$ directions respectively. Applying the FDM we get,

$$
\left(\frac{\partial U}{\partial \bar{t}}\right)_{i, j}=\frac{U_{i, j+1}-U_{i}}{\gamma},\left(\frac{\partial U}{\partial Y}\right)_{i, j}=\frac{U_{i+1, j}-U_{i-1, j}}{2 h},\left(\frac{\partial^{2} U}{\partial Y^{2}}\right)_{i, j}=\frac{U_{i-1, j}-2 U_{i, j}+U_{i+1, j}}{h^{2}}
$$

FDM for energy equation, $\left(\frac{\partial \bar{T}}{\partial \bar{t}}\right)_{i, j}=\frac{\bar{T}_{i, j+1}-\bar{T}_{i, j}}{\gamma},\left(\frac{\partial \bar{T}}{\partial Y}\right)_{i, j}=\frac{\bar{T}_{i+1, j}-\bar{T}_{i-1, j}}{2 h},\left(\frac{\partial^{2} \bar{T}}{\partial Y^{2}}\right)_{i, j}=\frac{\bar{T}_{i-1, j}-2 \bar{T}_{i, j}+\bar{T}_{i+1, j}}{h^{2}}$

From the continuity equation we have taken $V$ which may assume as unchanged velocity.

$$
U_{i, j+1}=U_{i}+\gamma\left[-V \frac{U_{i+1, j}-U_{i-1, j}}{2 h}+\frac{n}{R e h^{2}} \frac{U_{i-1, j}-2 U_{i, j}+U_{i+1, j}}{h^{2}}+G r \bar{T}_{i, j}-M U_{i, j}\right]
$$



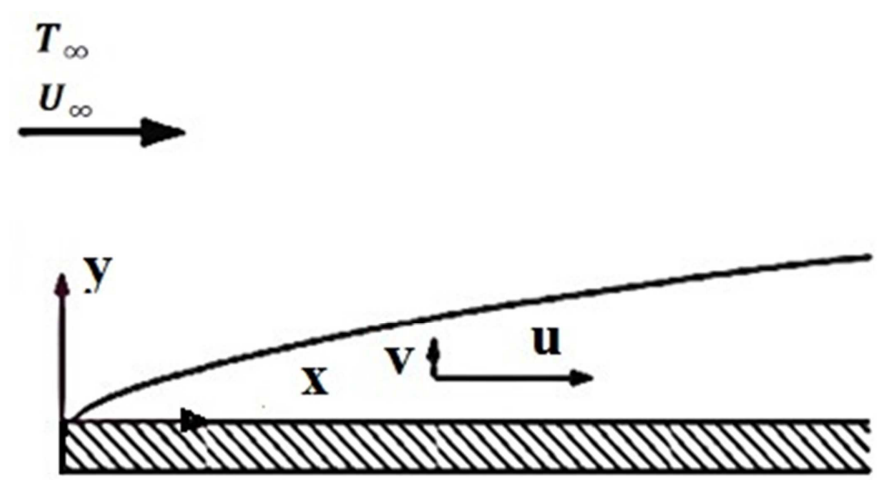

Figure 1. Physical Model of Boundary Layer.

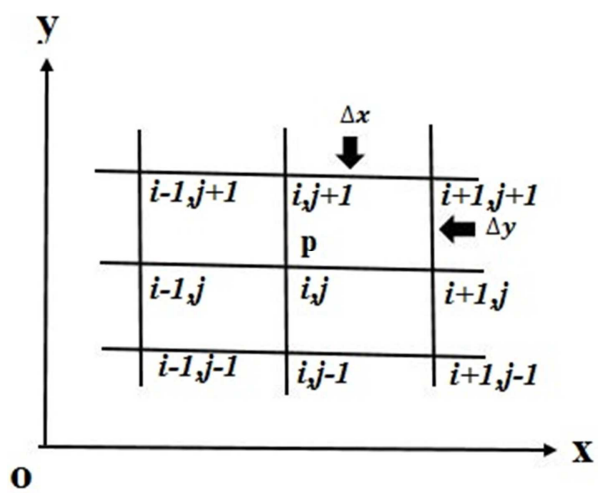

Figure 2. Numerical Grid System.

$$
\frac{\bar{T}_{i, j+1}-\bar{T}_{i, j}}{\gamma}+V \frac{\bar{T}_{i+1, j}-\bar{T}_{i-1, j}}{2 h}=\frac{1}{\operatorname{PrRe}} \frac{\bar{T}_{i-1, j}-2 \bar{T}_{i, j}+\bar{T}_{i+1, j}}{h^{2}}+\frac{E c}{\operatorname{Re}}\left(\left|\frac{U_{i+1, j}-U_{i-1, j}}{2 h}\right|^{n-1} \frac{U_{i+1, j}-U_{i-1, j}}{2 h}\right)^{2}
$$

$$
\text { for } i=1,2, \ldots m \text { and } j=1,2, \ldots r
$$

Initial conditions: $\bar{t}=0 \quad U_{i, 0}=0, \bar{T}_{i, 0}=0\left(\frac{\partial U}{\partial Y}\right)_{i, 0}=$ 0 and $\left(\frac{\partial \bar{T}}{\partial Y}\right)_{i, j}=0$ for $i=1,2, \ldots m$

Boundary conditions: $\bar{t}>0, U_{0, j}=1, \bar{T}_{i, 0}=1$ where $Y=$ $0, U_{m+1, j}=0, \bar{T}_{r+1, j}=0$ where $Y \rightarrow \infty, j=1,2, \ldots r$

Here the subscripts $i$ designate the grid points with $X$ coordinate and the subscripts $j$ for time steps at $Y$ direction.

For engineering interest skin friction coefficient $\left(C_{f}\right)$ and local Nusselt number $(\mathrm{Nu})$ which indicate physically wall shear stress and local wall heat transfer respectively.

The shear stress at the wall is, $\tau_{w}=\left.K\left(\left|\frac{\partial u}{\partial y}\right|^{n-1} \frac{\partial u}{\partial y}\right)\right|_{y=0}$ and the skin friction coefficient is, $C_{f}=\frac{\tau_{w}}{\frac{1}{2} \rho U_{0}{ }^{2}}$

Using transformations, we get the skin friction coefficient,

$$
\begin{gathered}
C_{f}=\left.2 \frac{K}{\rho} \frac{1}{U_{0}{ }^{2}}\left(\frac{U_{0}}{L}\right)^{n}\left(\left|\frac{\partial u}{\partial y}\right|^{n-1} \frac{\partial u}{\partial y}\right)\right|_{y=0} \\
\text { i.e. } C_{f}=\frac{2}{R e}\left\{\begin{array}{c}
-\left(-\frac{\partial u}{\partial y}\right)^{n}, \frac{\partial u}{\partial y}<0 \\
\left(\frac{\partial u}{\partial y}\right)^{n}, \frac{\partial u}{\partial y} \geq 0
\end{array} \text { at } Y=0\right.
\end{gathered}
$$

Using forward difference approximation, let us discretize the equation

$$
C_{f}=\frac{2}{R e}\left\{\begin{array}{c}
\left(\frac{U_{1, r}-U_{0, r}}{h}\right)^{n}, \text { if } U_{1, q} \geq U_{0, r} \\
-\left(\frac{U_{0, q}-U_{1, r}}{h}\right)^{n}, \text { if } U_{1, q}<U_{0, r}
\end{array}\right.
$$

Thus, the Nusselt number is given by, $N u=\frac{h L}{\gamma}$. Fourier's law the wall heat flux is given by, $q_{\text {wall }}=-\left.k \frac{\partial T}{\partial y}\right|_{y=0}$

Where, the thermal conductivity of the fluid is $k$. Again using Newton's law of cooling, we get, $q_{\text {wall }}=h\left(T_{w}-T_{\infty}\right)$ Where, $\mathrm{h}$ is the convective heat transfer coefficient of the fluid. Finally using those relation we can calculate the
Nusselt number, $\quad N u=-\left.\frac{L}{\left(T_{w}-T_{\infty}\right)} \frac{\partial T}{\partial y}\right|_{y=0}$. Using the transformations, we obtain, the dimensionless form of $N u$.

$$
N u=-\left.\frac{L}{\left(T_{w}-T_{\infty}\right)} \frac{\left(T_{w}-T_{\infty}\right)}{L} \frac{\partial \bar{T}}{\partial y}\right|_{y=0} \quad ; \quad N u=-\left.\frac{\partial \bar{T}}{\partial y}\right|_{y=0}
$$

Ultimately, we will use it after transforming it into finite difference approximation.

Hence, temperature gradient will be $N u=\frac{\bar{T}_{0, m}-\bar{T}_{1, r}}{h}$

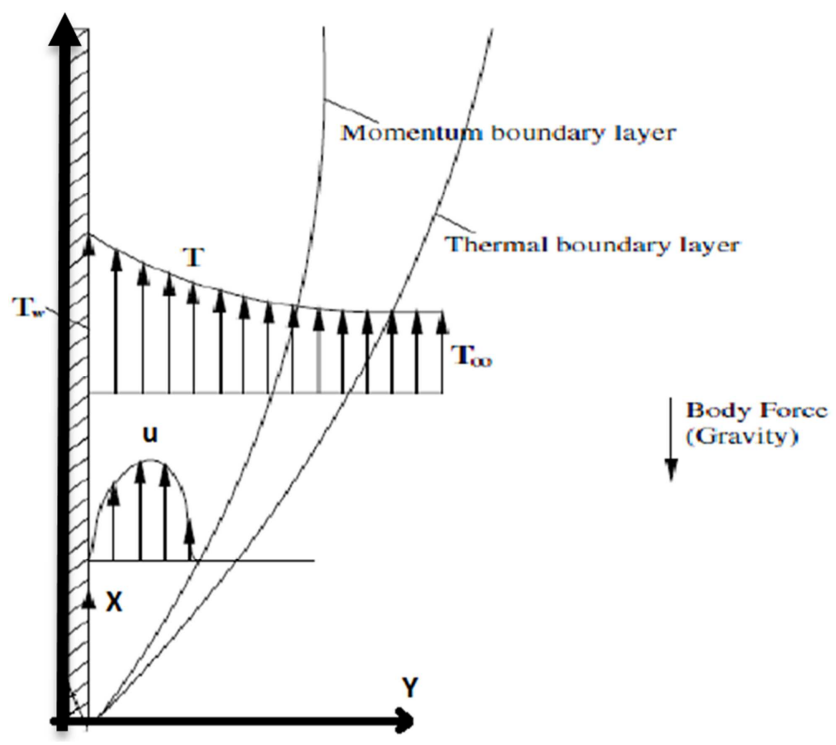

Figure 3. Model of boundary layer in a vertical plate.

\section{Results Analysis}

Here, we have to use boundary conditions and dimensionless numbers to draw figures. In each case, figure has been drawn for $Y$ scale. Temperature $T$ and velocity profile $U$ have been drawn for each parameter to show the effect properly. The outcomes are determined by the numerical solution of the boundary layer equations. It is found that, the interaction between the viscous heating and the buoyancy force has a strong influence on the results. Grashof 
number $(G r)$ plays the similar role in free convection that Reynolds number $(R e)$ does in forced convection. From the definition of Grashof number, it provides the ratio of buoyancy force to the viscous force acting on the fluid. Analysis has been carried out for different parameters. According to Figure 4, 5 and 6, we observe that, an increase in Grashof number leads to an increase in velocity profiles adjacent to the plate and a decrease away from the plate. In case of dilatant fluid $(n=1.5)$, we observe the maximum increase of velocity profile. There is no significant effect of Grashof number for the variation of temperature because there was no Grashof number term in the energy equation. The effects of magnetic field on velocity and temperature profile are shown in Figure 7, 8, and 9 for different power law indices $(n)$. Since, we have taken a free convection case, then the magnitude of magnetic parameter is very low for these types of laminar flow. Velocity profiles are decreased as magnetic field parameter increased. However, there is no such effect found on temperature profile. For large time period, increment of $\mathrm{M}$ induced to decreased the velocity apparently which ultimately helps to fall the viscous dissipation. From Figure 10, 11 and 12, we investigated that, the Prandlt number $(\mathrm{Pr})$ has a great effect on both velocity and temperature profile. Cross flows have been found in temperature profile for various $\operatorname{Pr}$ (Figure 14-15). M has a significant effect on the steady state time and this effect is more distinct for higher values of $M$. From the definition of Eckert number, it implies the ratio of advective transport and heat dissipation potential. It expresses the relationship between a flow's kinetic energy and the boundary layer enthalpy difference, and is used to characterize heat dissipation. The influences of Eckert number $E c$ on velocity and temperature profiles are depicted in Figure 16 to 21, which shows significant effect for increase of Eckert number. For Newtonian fluid and dilatant fluid the variation of momentum boundary layer increases with the increment of Eckert number $E c$ but the rate of increment is constant. For free convection the highest peak of velocity profile for $n=1$. There is very small effect of temperature profile $T$ for the variation of Eckert numbers $(E c)$, except at the mid points of the Figure 19, 20 and 21 . The changes are little and rate of increment is constant for each and every type of fluid. The graph of Velocity profile has increased with the positive increment of Eckert number $E c$. For each and every case the temperature profile has increased with the growth of the Eckert number $E c$.

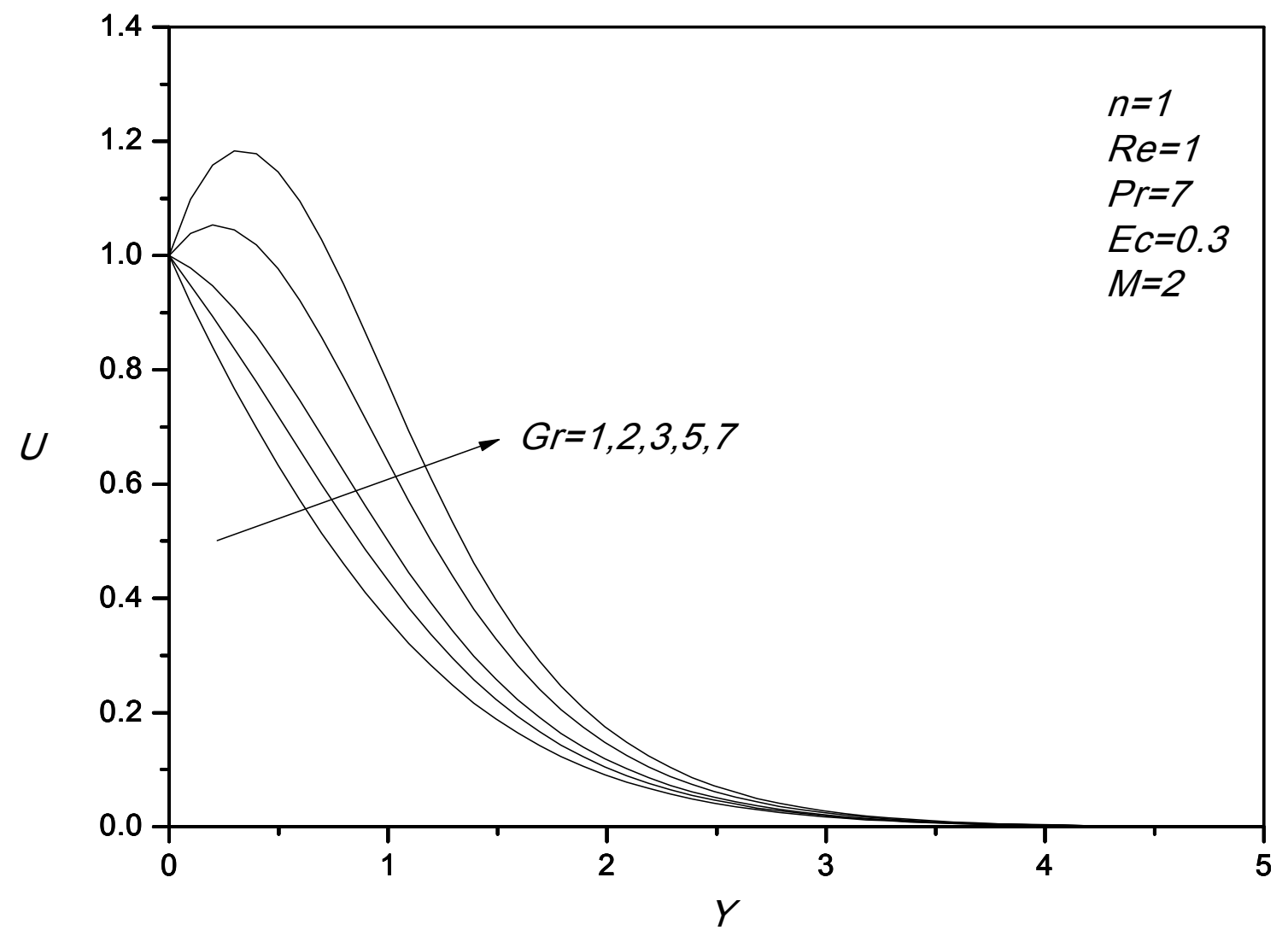

Figure 4. Effect of Grashof number Gr on U for Newtonian Fluid. 


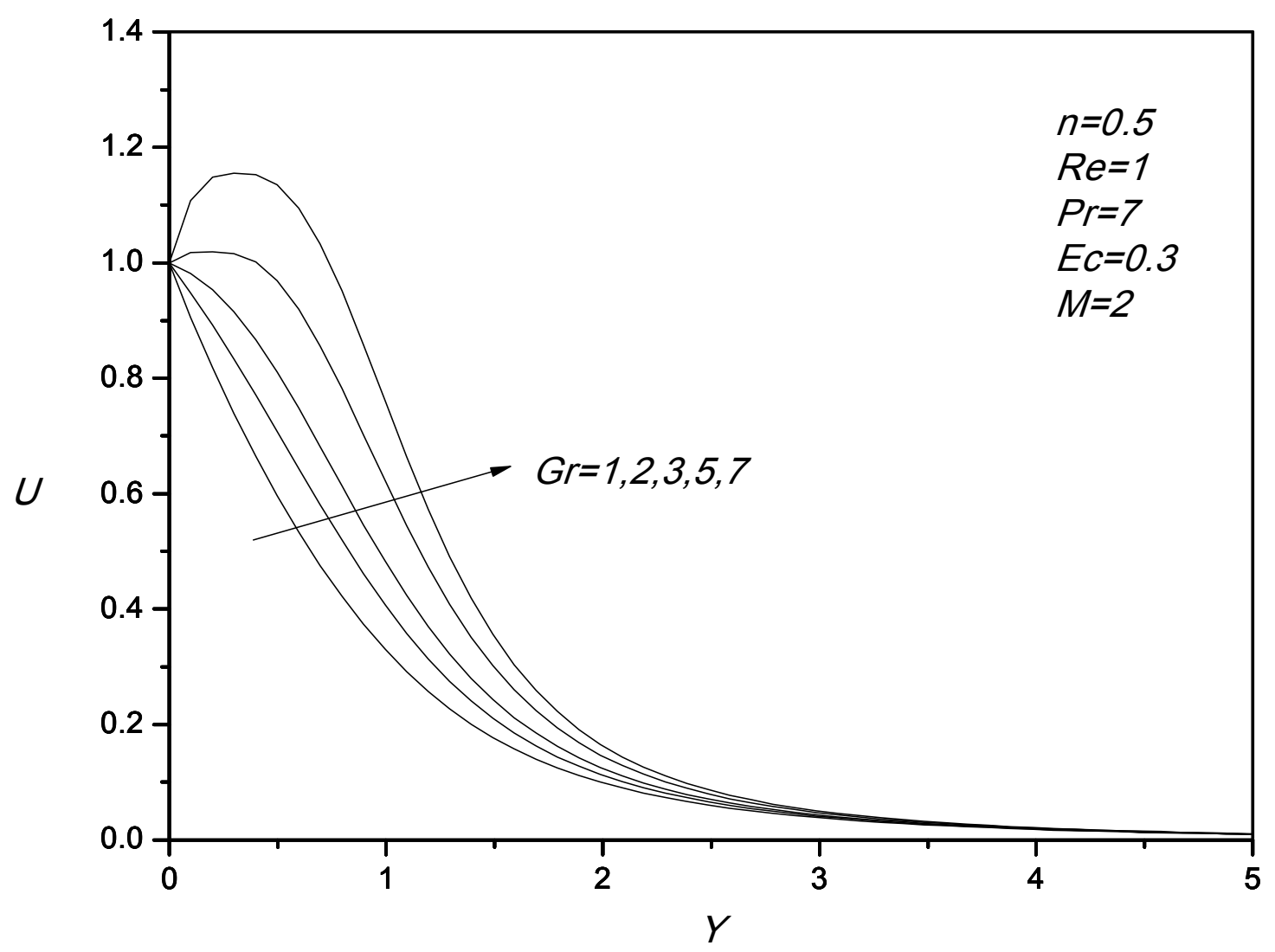

Figure 5. Effect of Grashof number Gr on U for Pseudo plastic Fluid.

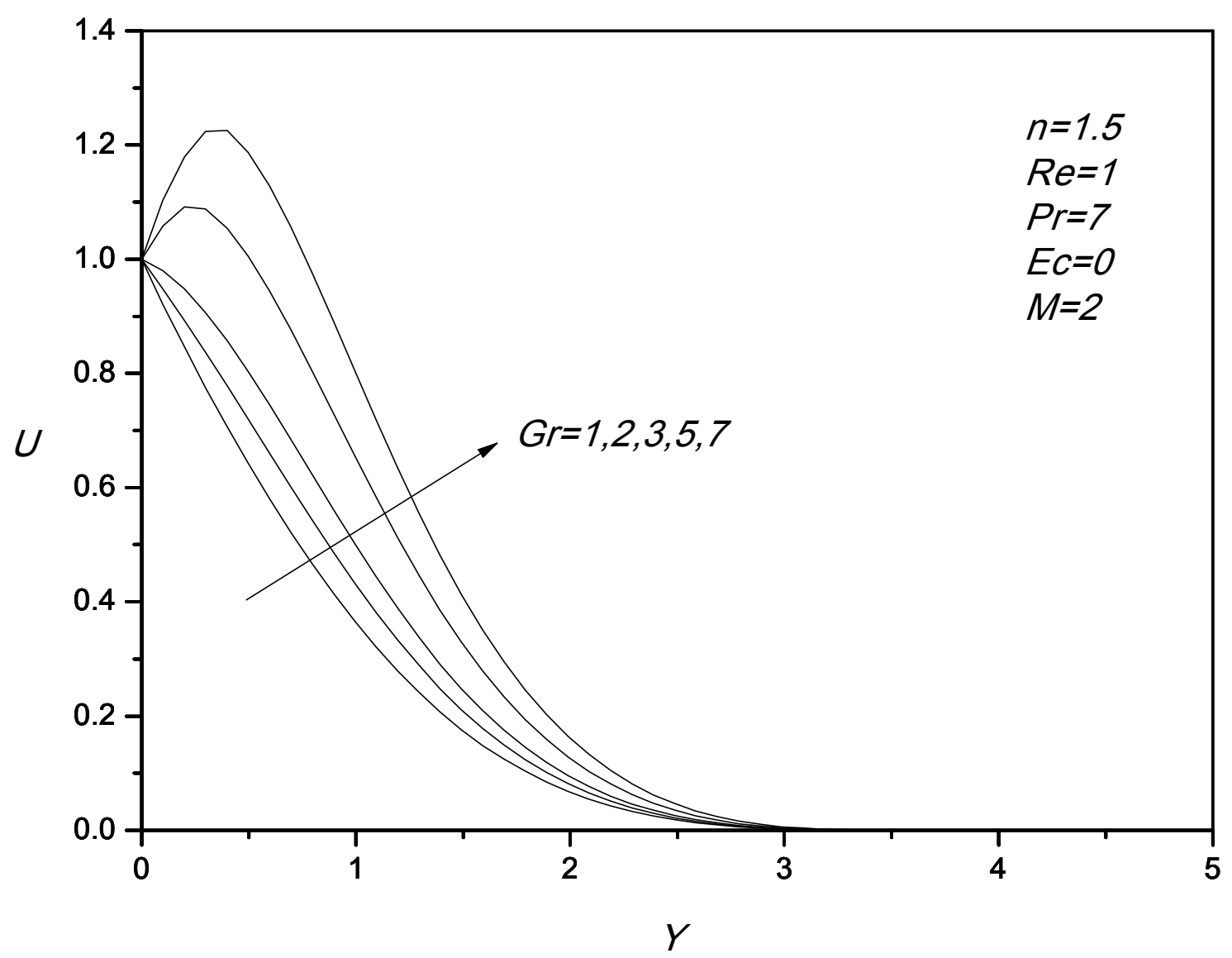

Figure 6. Effect of Grashof number Gr on U for Dilatant Fluid. 


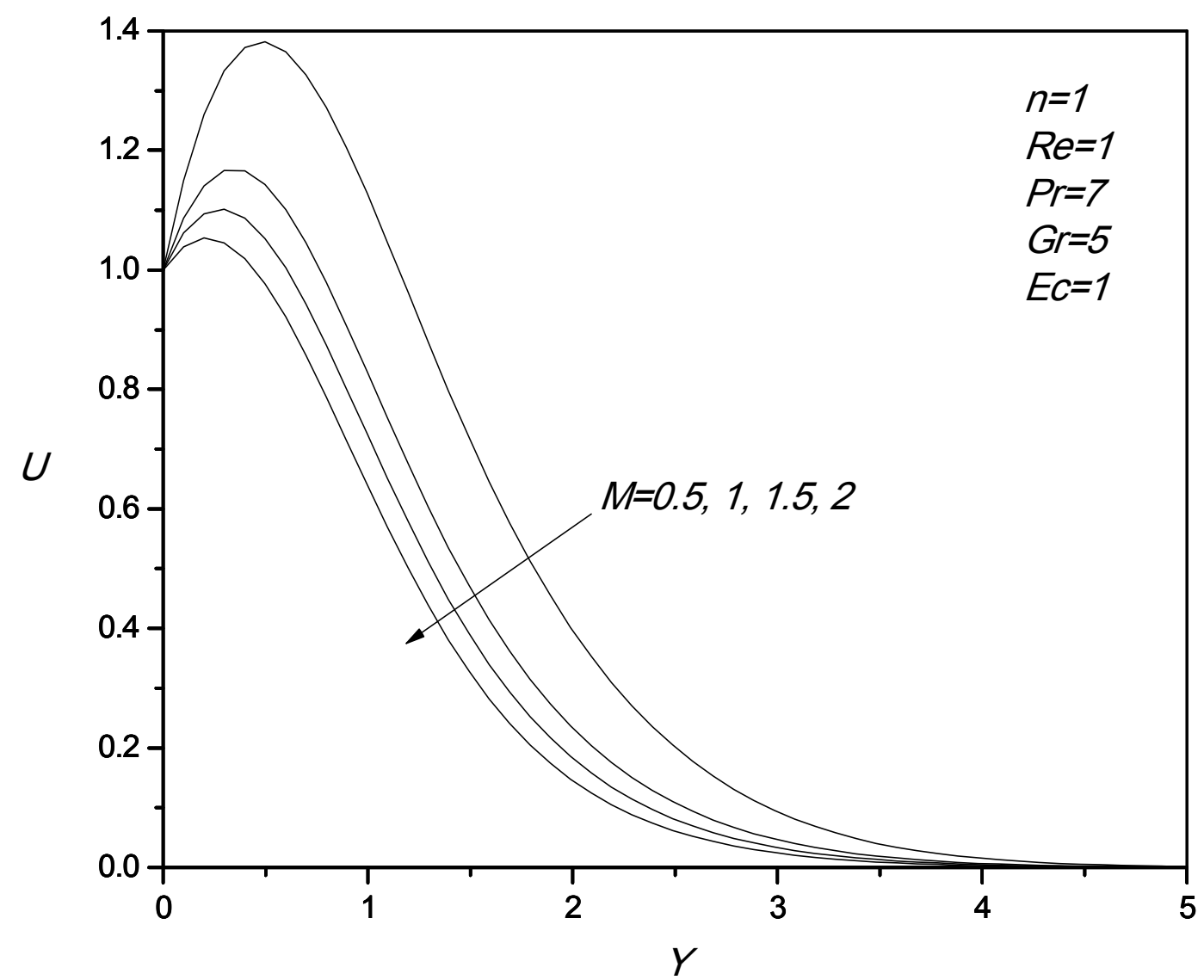

Figure 7. Effect of magnetic parameter M on U for Newtonian Fluid.

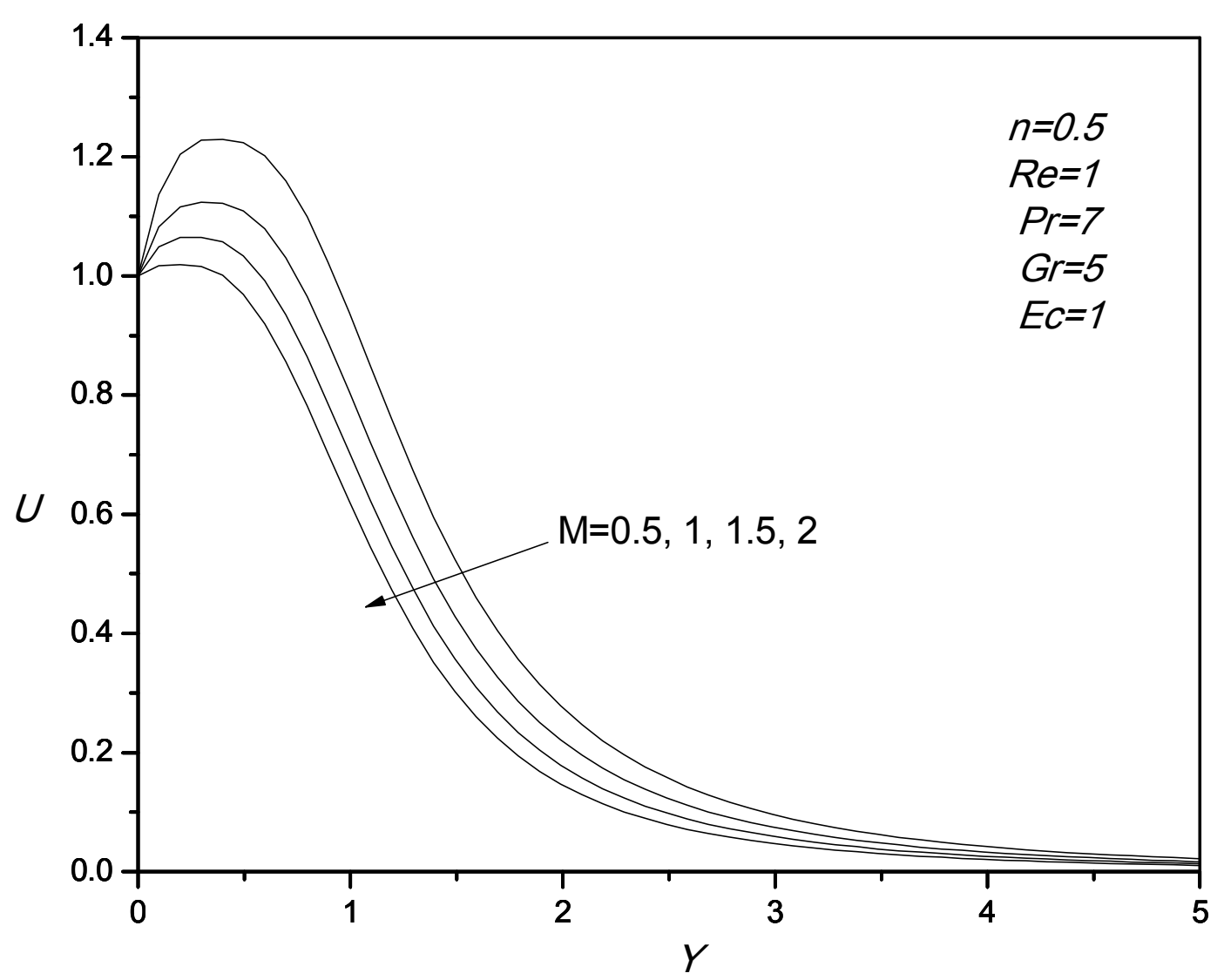

Figure 8. Effect of magnetic parameter M on U for Pseudo plastic Fluid 


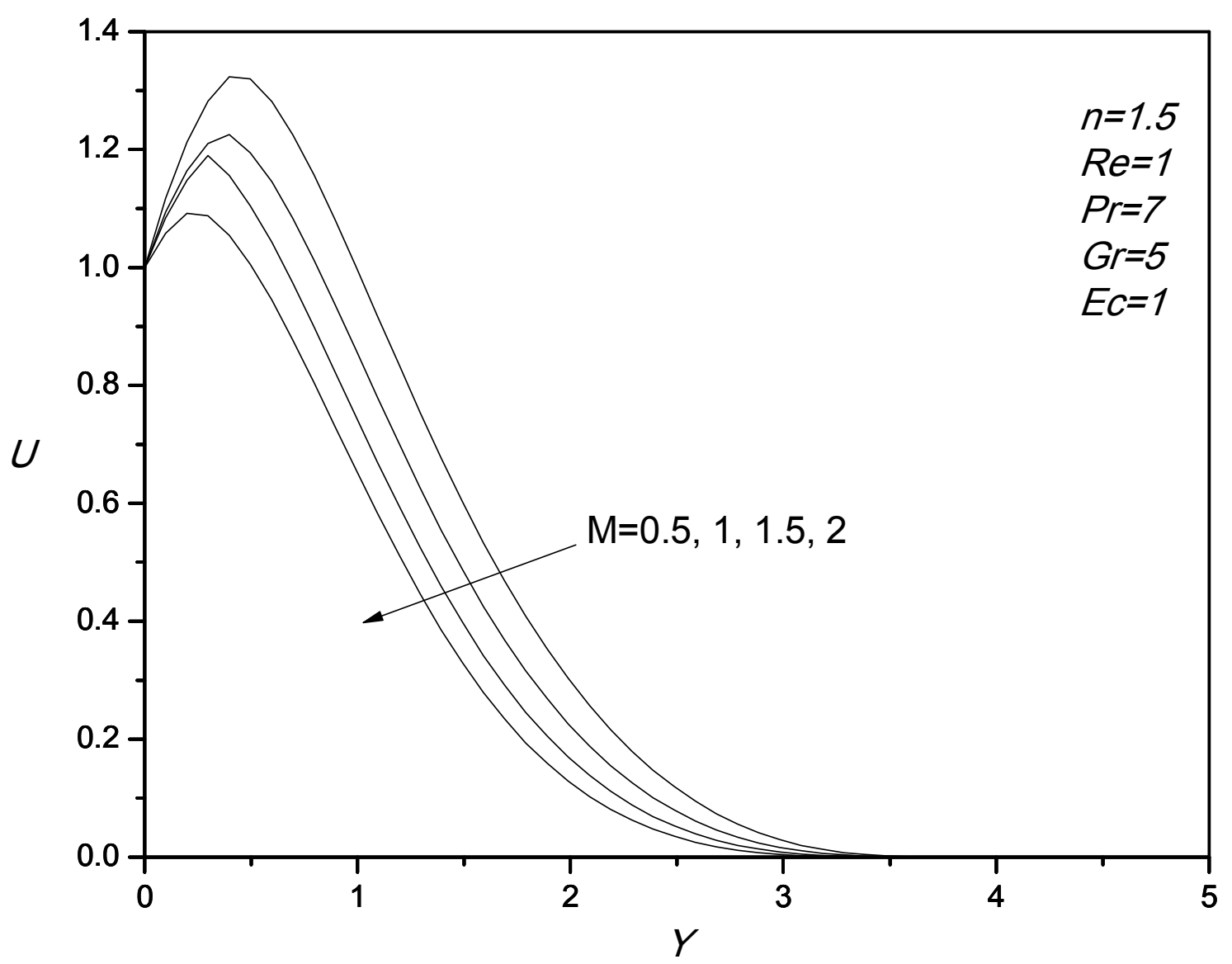

Figure 9. Effect of magnetic parameter M on U for Dilatant Fluid.

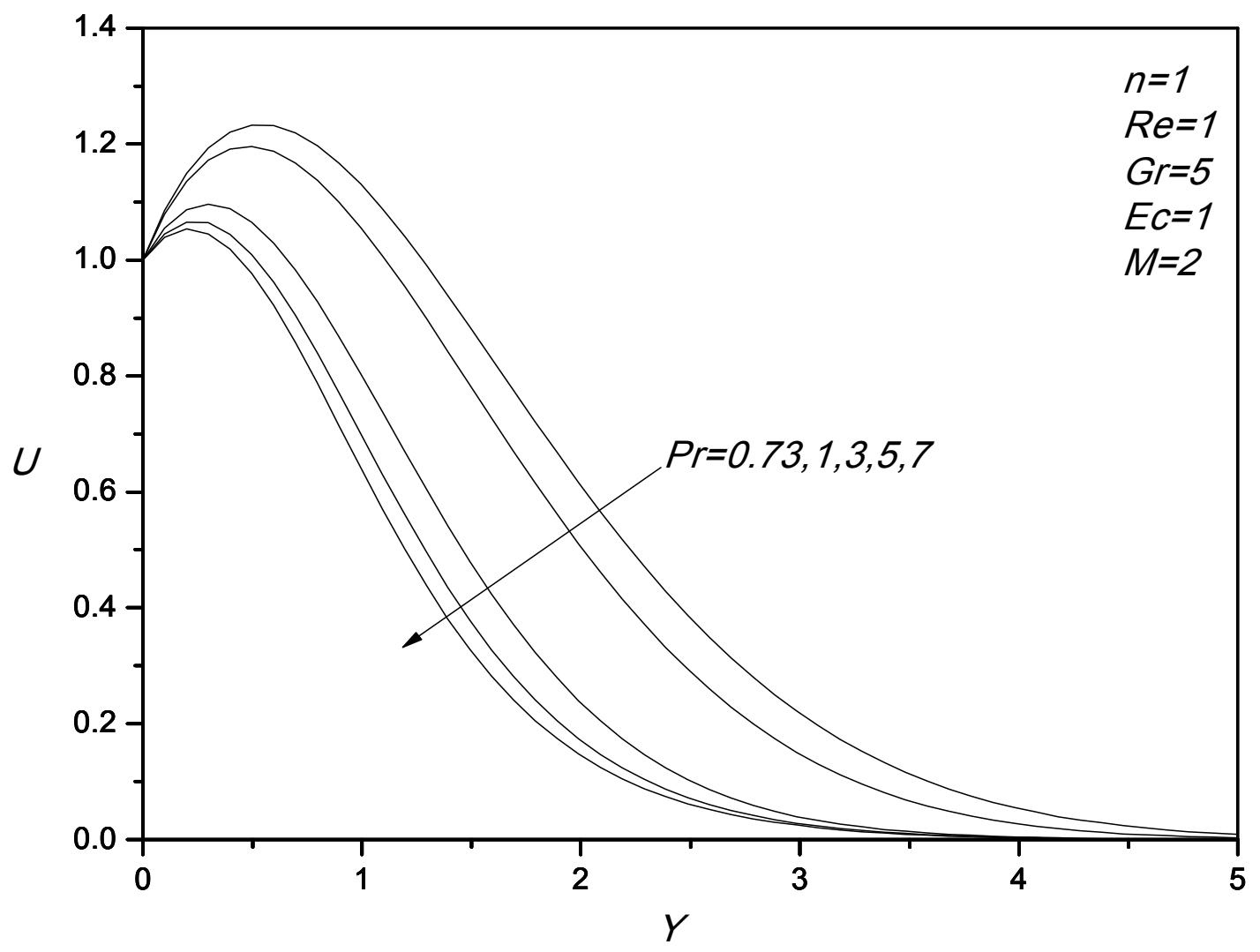

Figure 10. Effect of Prandtl number Pr on U for Newtonian Fluid. 


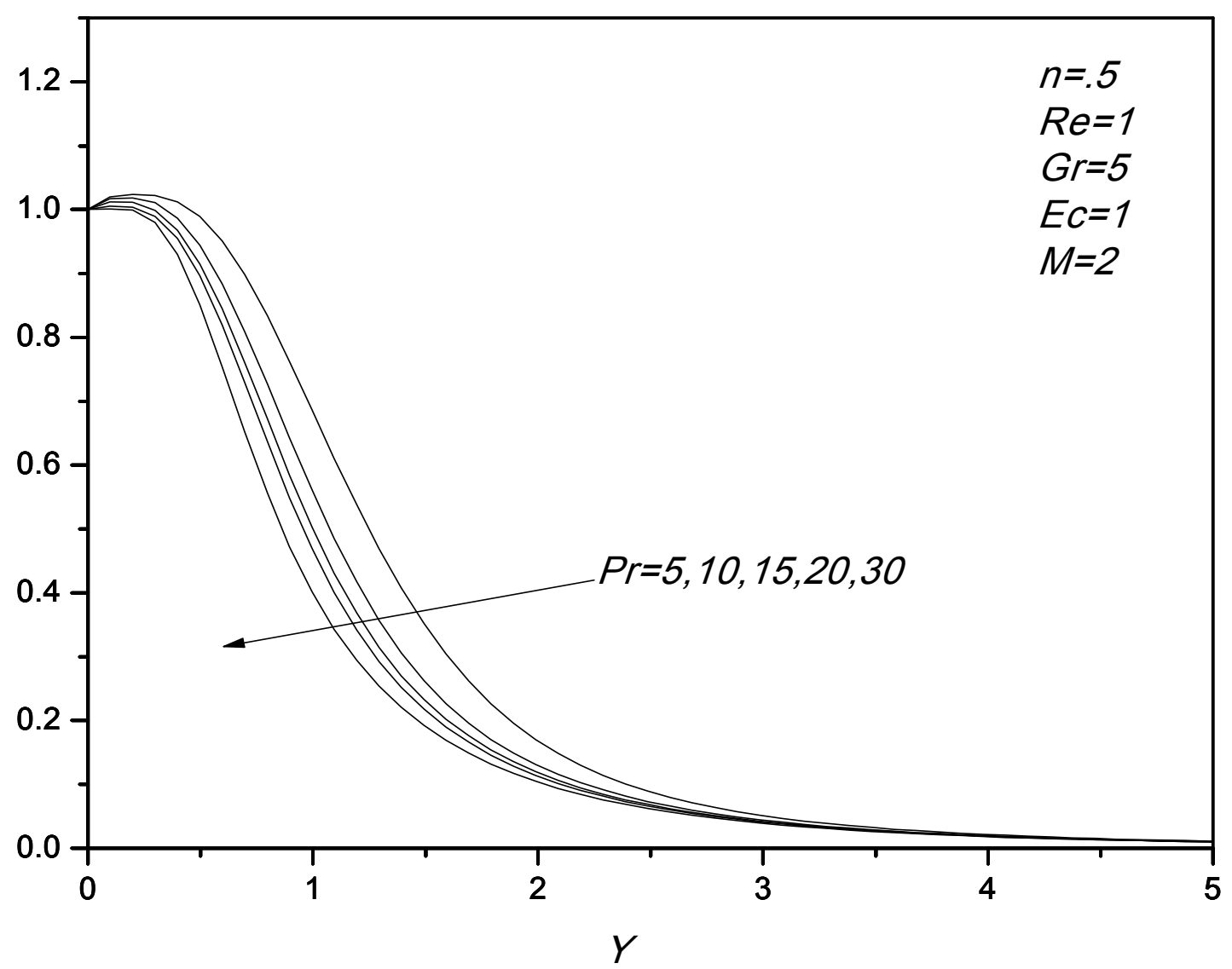

Figure 11. Effect of Prandtl number Pr on U for Pseudo plastic Fluid.

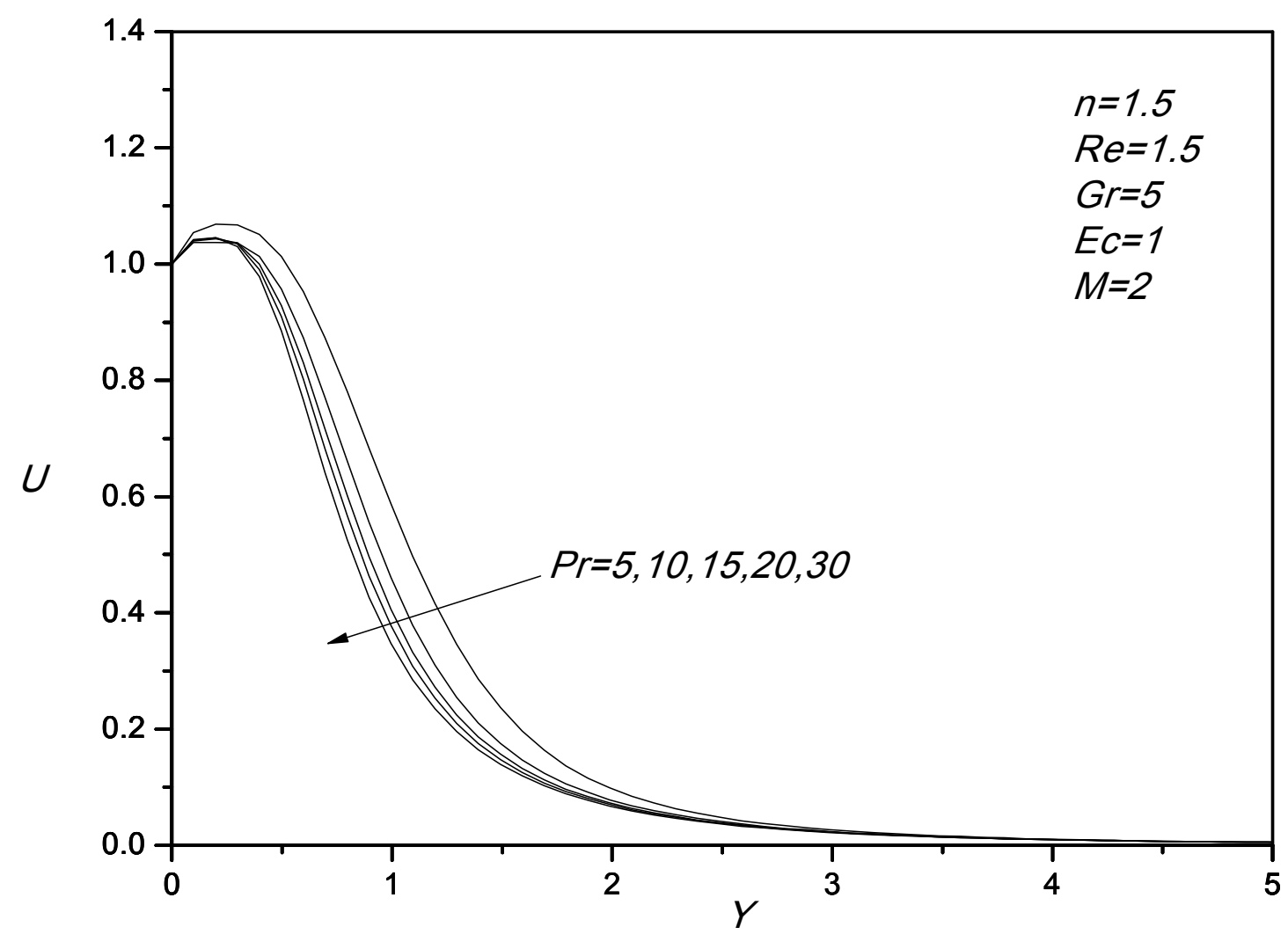

4.3. (c)

Figure 12. Effect of Prandtl number Pr on U for Dilatant Fluid. 


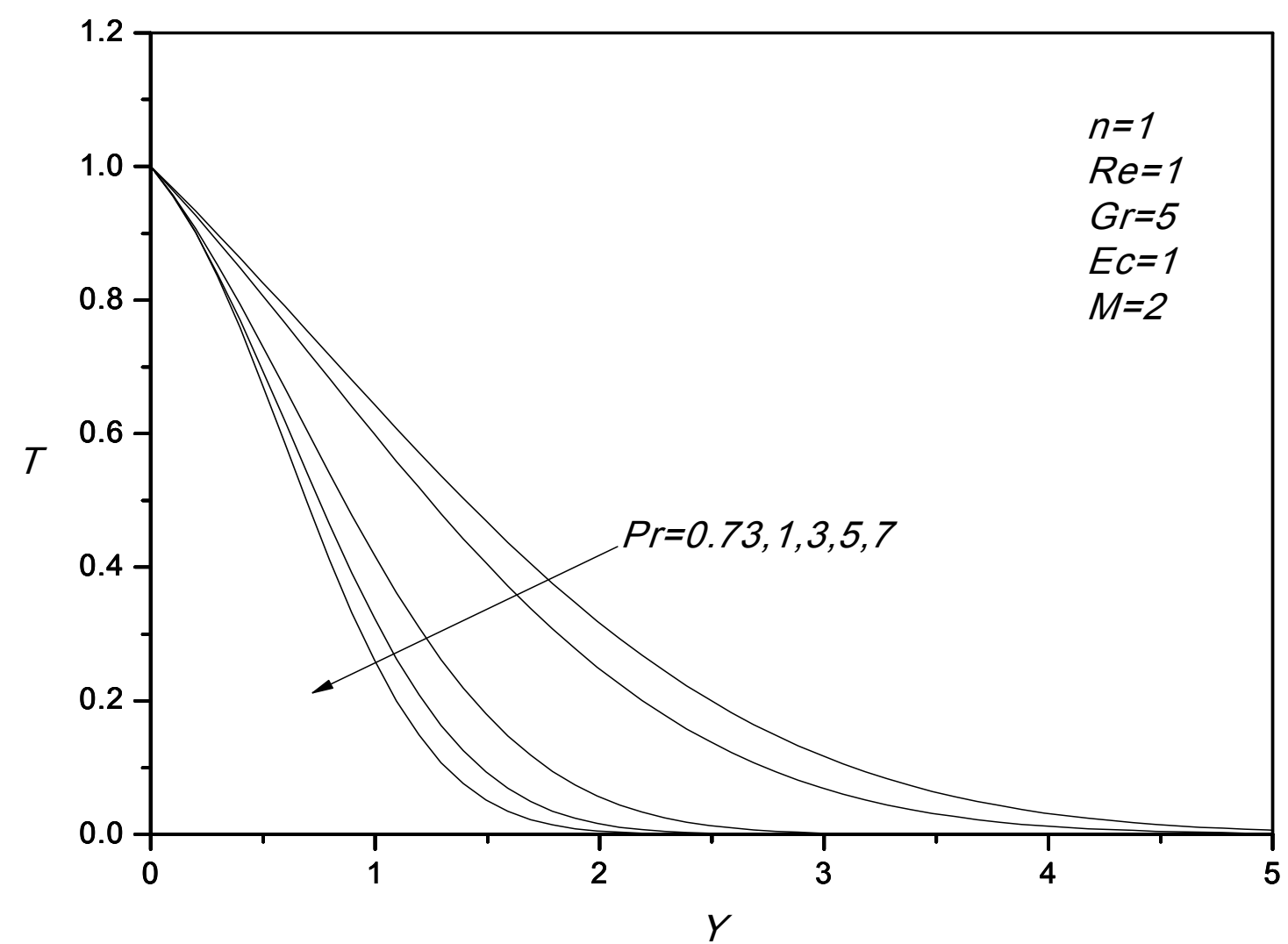

Figure 13. Effect of Prandtl number Pr on T for Newtonian Fluid.

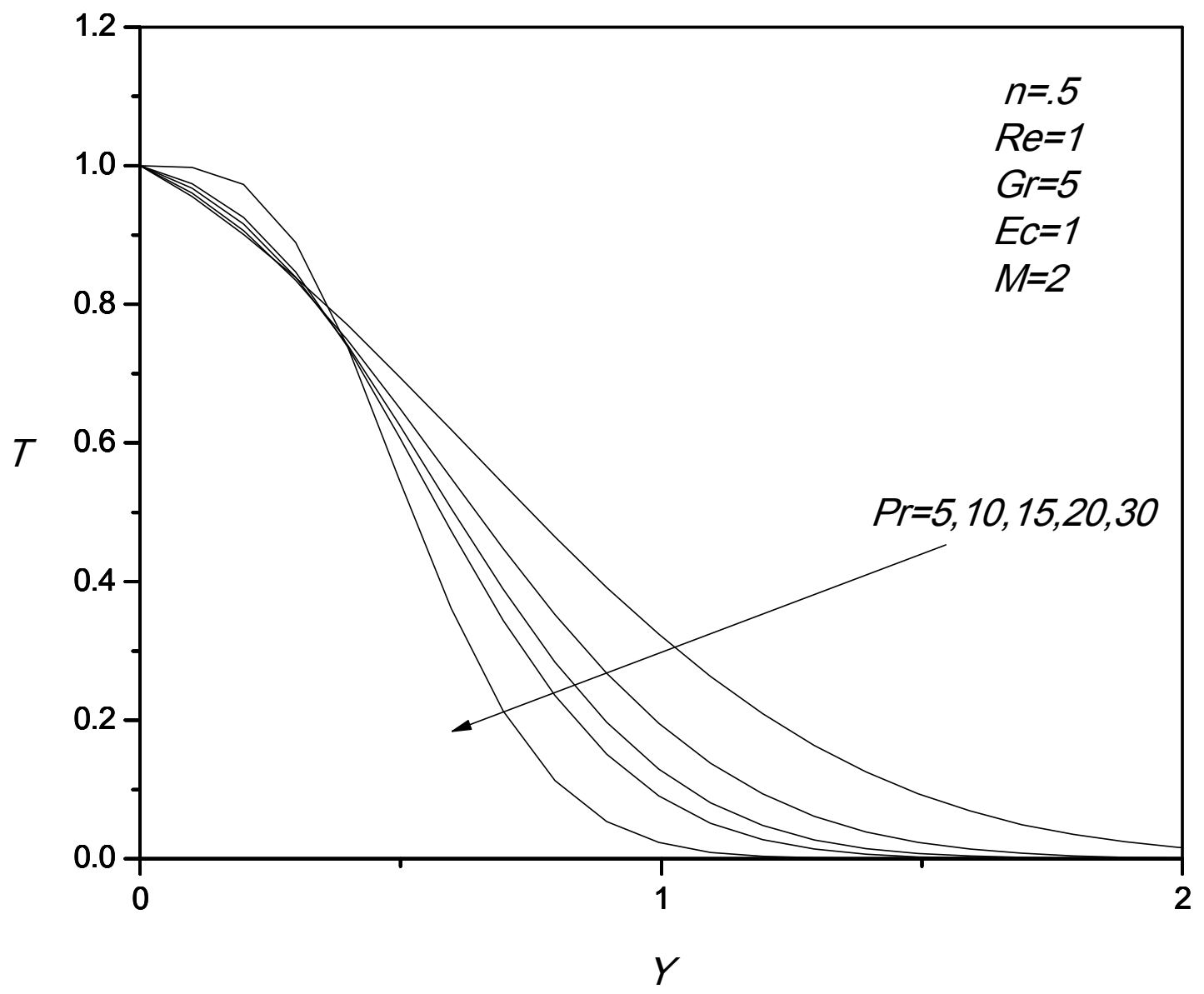

Figure 14. Effect of Prandtl number Pr on T for Pseudo plastic Fluid. 


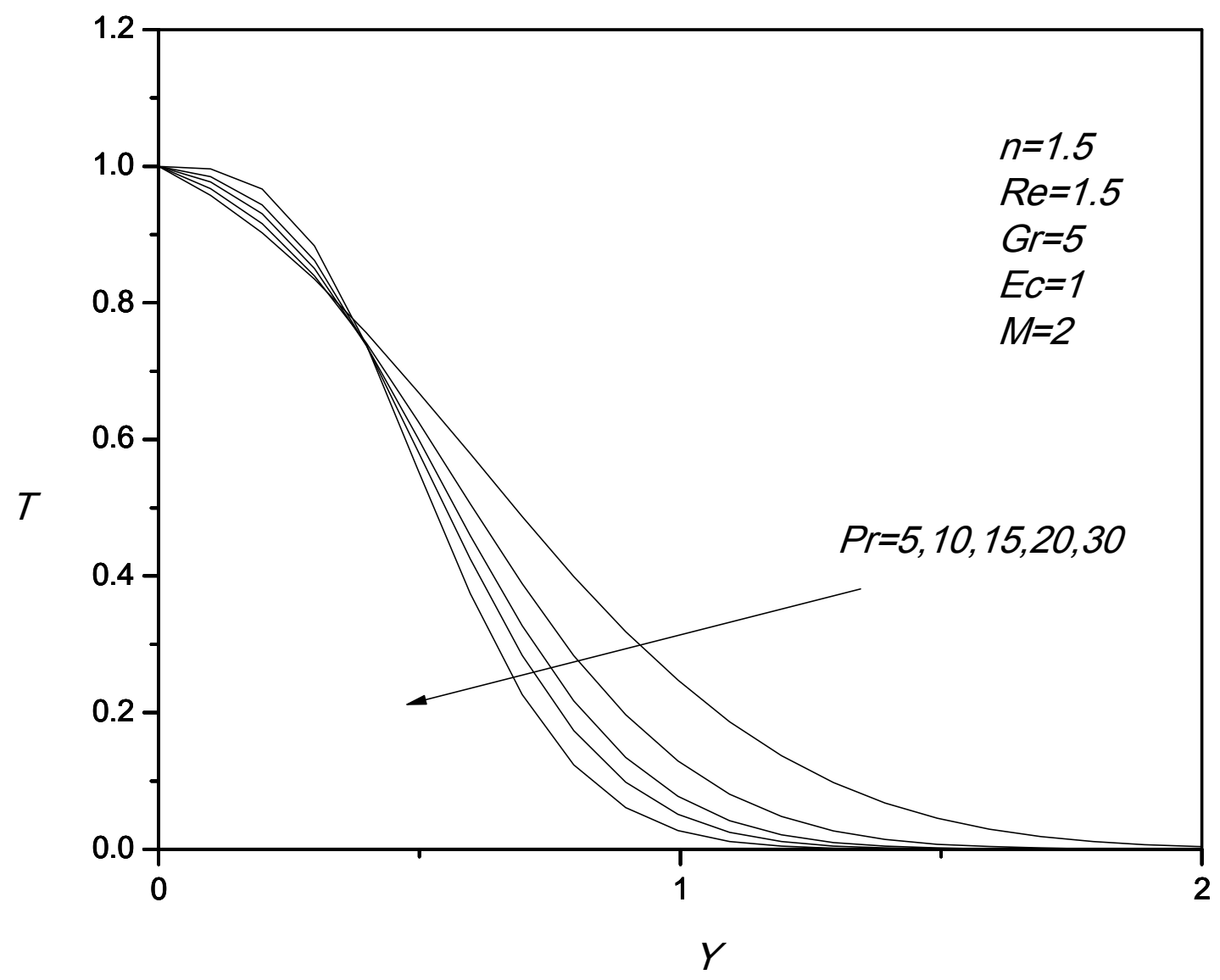

4.4. (c)

Figure 15. Effect of Prandtl number Pr on T for Dilatant Fluid.

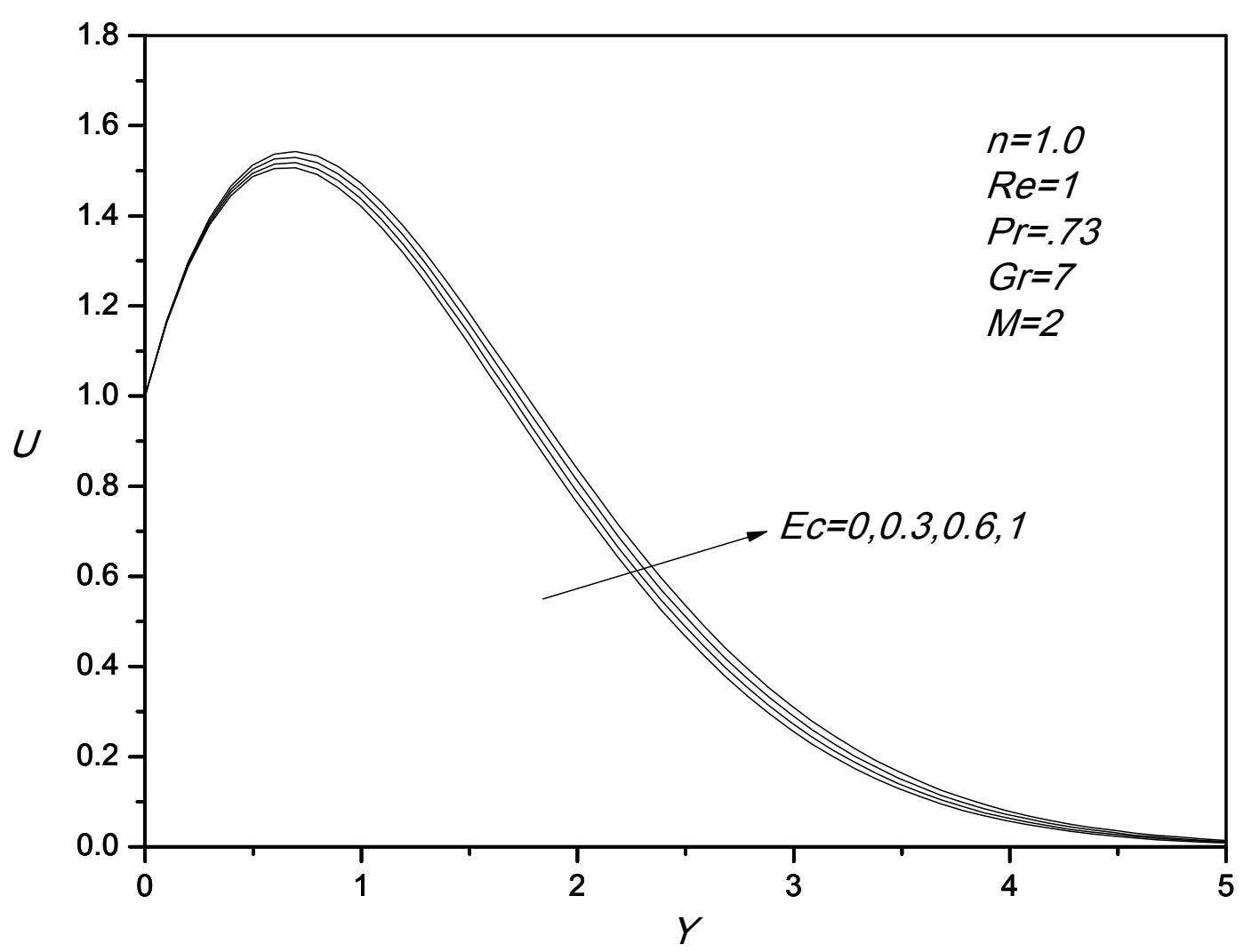

Figure 16. Effect of Eckert number Ec on U for Newtonian Fluid. 


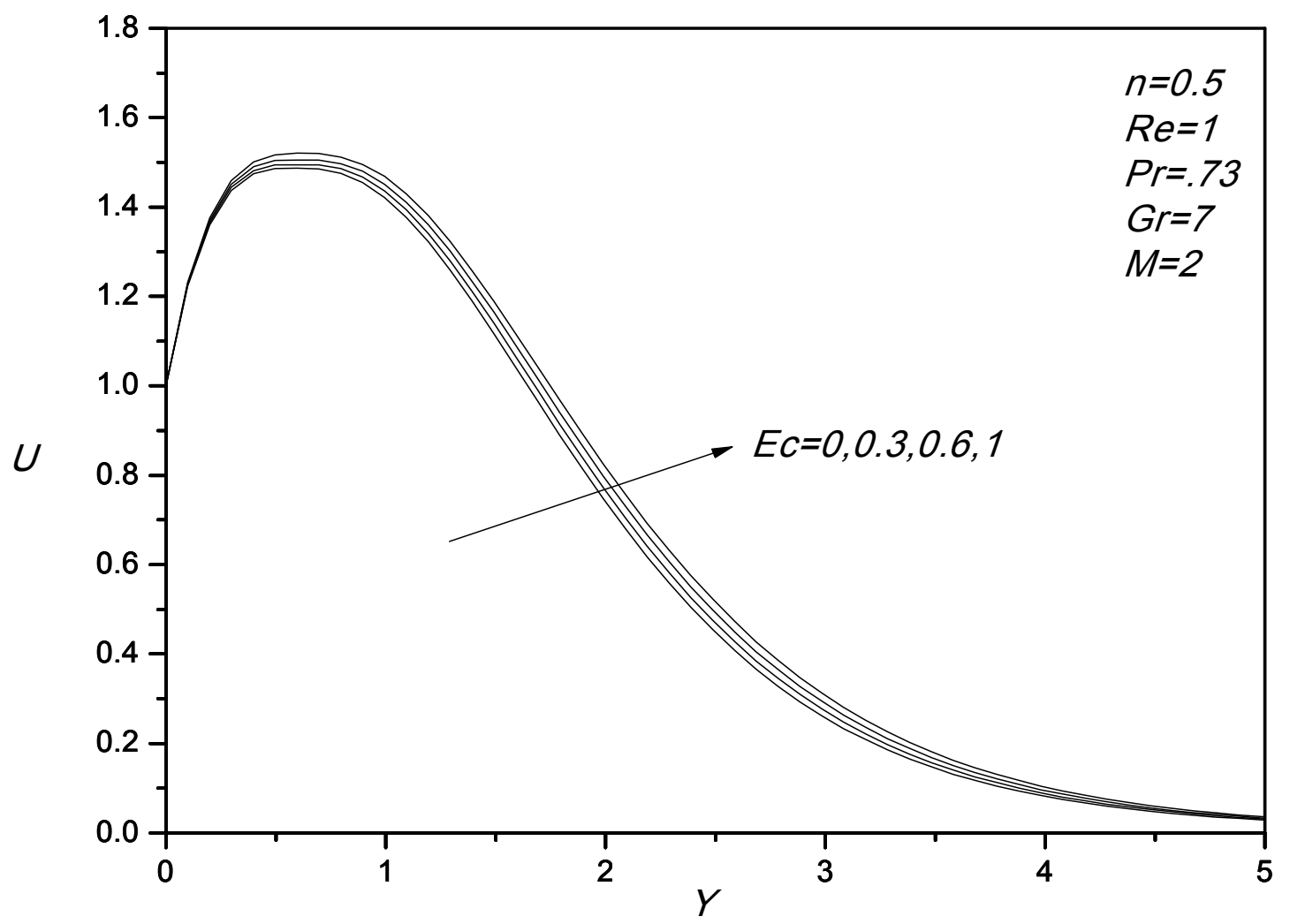

Figure 17. Effect of Eckert number Ec on U for Pseudo plastic Fluid.

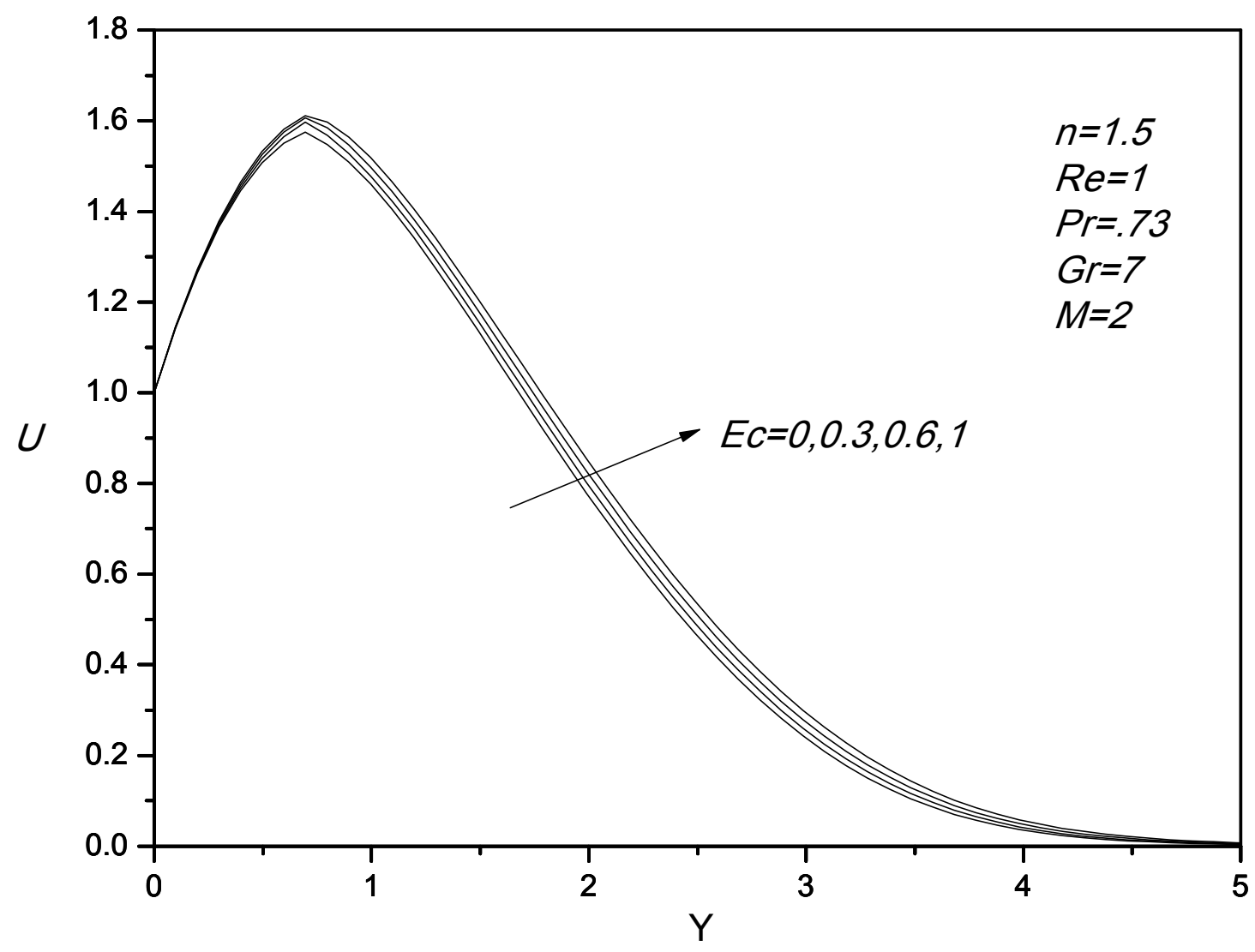

Figure 18. Effect of Eckert number Ec on U for Dilatant Fluid. 


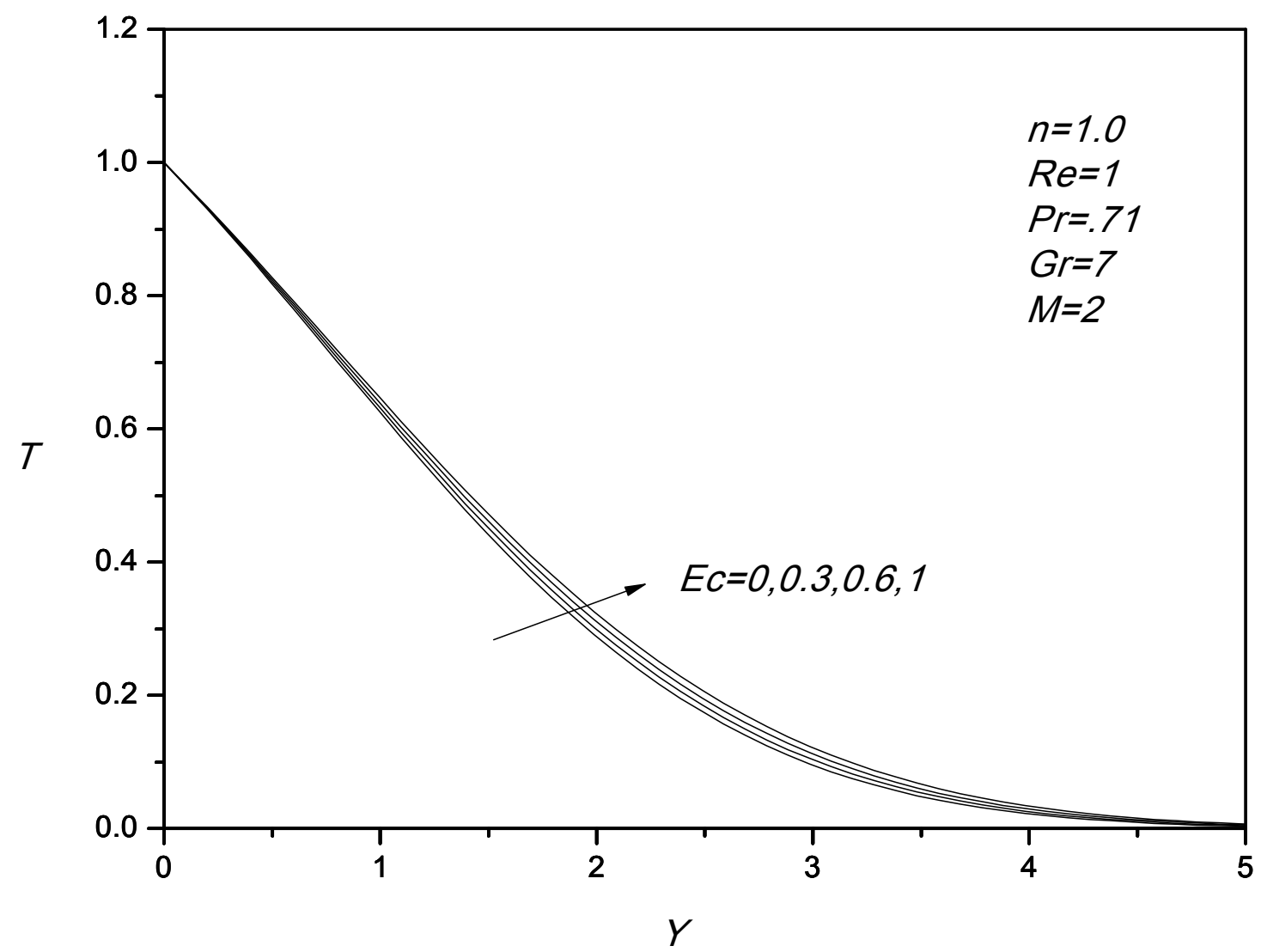

Figure 19. Effect of Eckert number Ec on T for Newtonian Fluid.

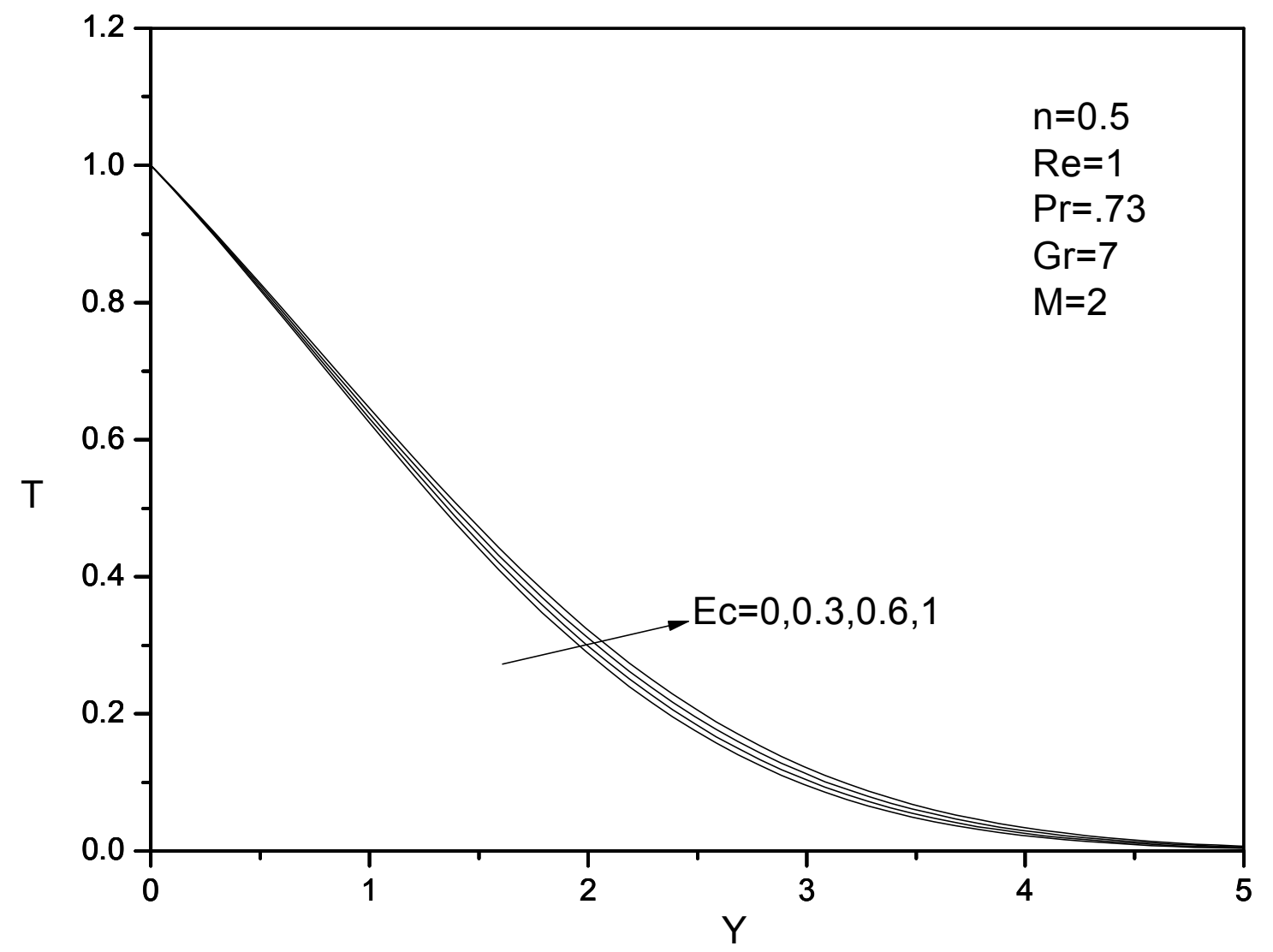

Figure 20. Effect of Eckert number Ec on T for Pseudo plastic Fluid. 


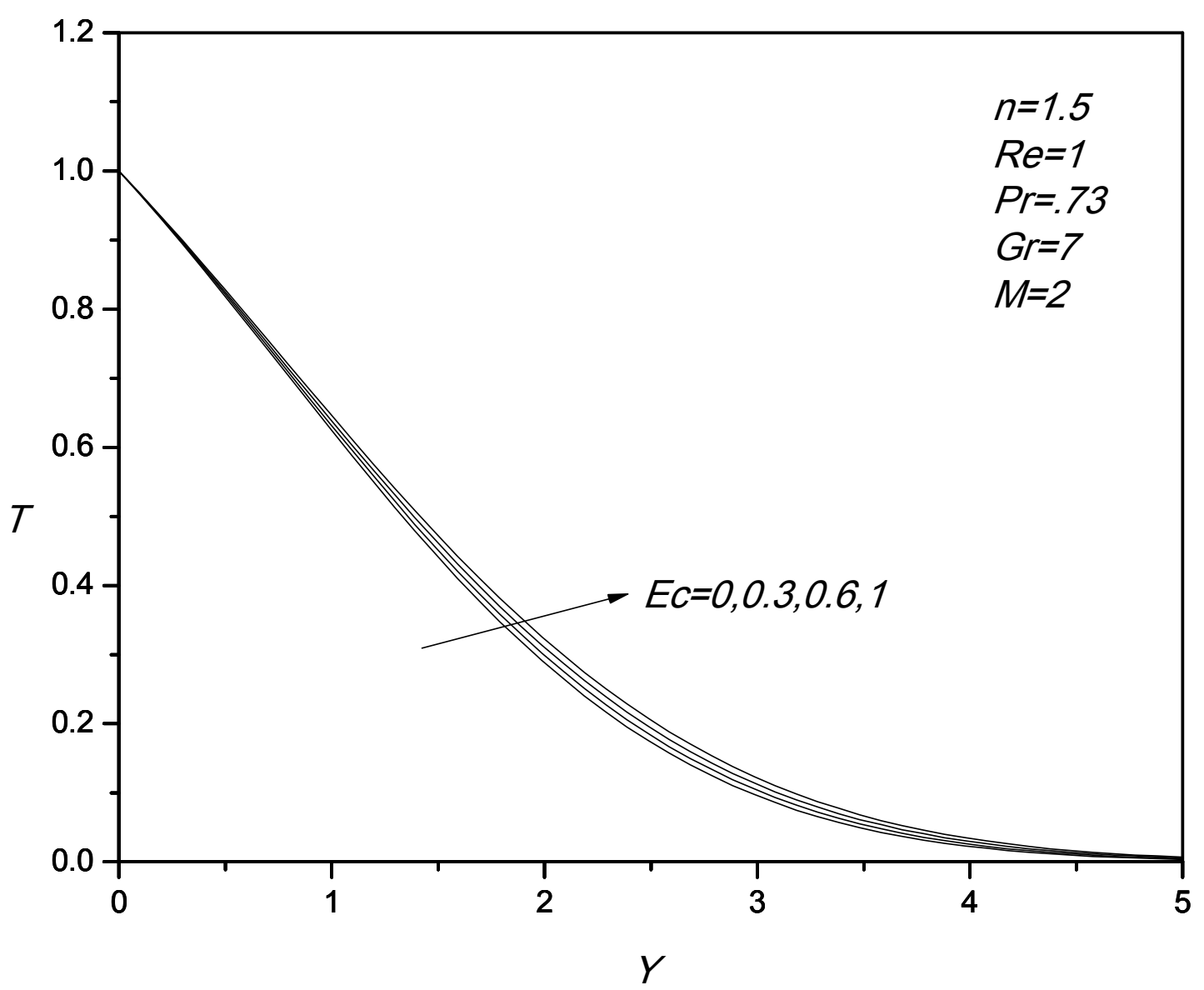

Figure 21. Effect of Eckert number Ec on T for Dilatant Fluid.

Table 2. Skin friction coefficient $\left(C_{f}\right)$ and Nusselt number $(N u)$ for different significant parameters.

\begin{tabular}{llllllllll}
\hline $\boldsymbol{n}$ & $\boldsymbol{M}$ & $\boldsymbol{C}_{\boldsymbol{f}}$ & $\boldsymbol{N}_{\boldsymbol{u}}$ & $\boldsymbol{P r}$ & $\boldsymbol{C}_{\boldsymbol{f}}$ & $\boldsymbol{N}_{\boldsymbol{u}}$ & $\boldsymbol{E} \boldsymbol{l}$ & $\boldsymbol{C}_{\boldsymbol{f}}$ & $\boldsymbol{N}_{\boldsymbol{u}}$ \\
\hline \multirow{4}{*}{0.5} & 0.5 & 2.34468355 & 0.4320557813 & 5 & 0.6022460472 & 0.4478886719 & 0 & 2.99717879 & 0.341713567 \\
& 1.0 & 1.820571767 & 0.4320743537 & 10 & 0.553246696 & 0.3944452944 & 0.3 & 3.01319858 & 0.337098074 \\
& 1.5 & 1.395953637 & 0.4320893282 & 15 & 0.4627652249 & 0.326943374 & 0.6 & 3.029829601 & 0.337200273 \\
& 2.0 & 0.839475350 & 0.4321007048 & 20 & 0.3138404482 & 0.2631350496 & 1.0 & 3.050152541 & 0.326924801 \\
& 0.5 & 3.006349563 & 0.4321522211 & 5 & 0.8640414804 & 0.4264213392 & 0 & 3.242318136 & 0.341745315 \\
1 & 1.0 & 1.736513571 & 0.4321522211 & 10 & 0.714947084 & 0.327152516 & 0.3 & 3.272981088 & 0.337115441 \\
& 1.5 & 1.236012516 & 0.4321522211 & 15 & 0.657491635 & 0.2315861198 & 0.6 & 3.304753560 & 0.332183062 \\
& 2.0 & 0.783776184 & 0.4321522211 & 20 & 0.62816654 & 0.1507917879 & 1.0 & 3.338210420 & 0.326924801 \\
& 0.5 & 2.575365002 & 0.4321090965 & 5 & 0.5416880142 & 0.4264081536 & 0 & 3.449986021 & 0.341712100 \\
1.5 & 1.0 & 1.833051443 & 0.4321090965 & 10 & 0.3025314125 & 0.3269966792 & 0.3 & 3.486650801 & 0.337095672 \\
& 1.5 & 1.544582356 & 0.4321090965 & 15 & 0.3402372325 & 0.2312648416 & 0.6 & 3.534585038 & 0.332172871 \\
& 2.0 & 0.890236095 & 0.4321090965 & 20 & 0.357896211 & 0.1507720196 & 1.0 & 3.582408510 & 0.326924801 \\
\hline
\end{tabular}

Table 2 shows numerical values of the skin friction coefficient $C_{f}$ and Nusselt number $N u$ for different values of magnetic parameter $M$ are chosen and power law fluid index $n$ while keeping other parameters are fixed. From the above Table 2, it can be decided that skin friction coefficient is decreasing with the positive increment of magnetic parameter $M$. As we know magnetic parameter is an important parameter to control velocity profiles $U$. So for this case we have chosen $M$ is between $0.5 \leq M \leq 2$ and the variation of temperature profiles $T$ remain unchanged. Notable change is observed in velocity profile. As skin friction coefficient $\left(C_{f}\right)$ is a gradient of velocity profile $U$. Thus, in this factor, $C_{f}$ has decreased significantly. But there is no such effect found for Nusselt number $(\mathrm{Nu})$. Details has been shown in Table 2. It shows numerical values of the skin friction coefficient $\left(C_{f}\right)$ and Nusselt number $(N u)$ for different values of Prandtl number $\mathrm{Pr}$ are chosen and power law fluid index $n$ while keeping other parameters are fixed. From the Table 2, we observe that, the skin friction and Nusselt number both decrease with the increment of Prandtl number. The velocity gradient and temperature gradient has changed significantly. The rate is also depend on flow 
behavior index $n$. That's mean from the above table, it is distinct that in case of Newtonian fluid $(n=1)$ skin friction coefficient has high magnitudes relative to non-Newtonian fluids. However, Nusselt number $(\mathrm{Nu})$ is maximum for pseudo plastic fluid $(n=0.5)$.

\section{Conclusion}

Buoyancy force reduces the thickness of velocity boundary layer. Skin friction coefficient has increased but Nusselt number remain unchanged for the growth of $G r$. Velocity profile decreases as $M$ increases in all types of fluids which reduce faster for Newtonian fluid compared to nonNewtonian fluids. $C_{f}$ reduces with the increment of $M$ but $\mathrm{Nu}$ remain unchanged. In the entire flow field $\mathrm{Pr}$ shows its effect significantly as well as cross flow has been found. Interaction between viscous heating and the buoyancy force has an influence on the outcomes. $E c$ has very small effect on both profile where $C_{f}$ and $N u$ shows opposite result. In existence of viscous dissipation, fluids of relatively small $\mathrm{Pr}$ has higher temperature than that of the channel plates (e.g. heat is being transferred from the fluid to the plate). Viscosity is very important to control thermal boundary layer. However for specific engineering interest, concentration equation can be used. Values of dimensionless numbers and different parameters have been considered from different fluid.

\section{Acknowledgements}

We, the researchers of this small research work, appreciate the department of applied mathematics of University of Dhaka for providing us necessary supports.

\section{References}

[1] Sakiadis. B. C, "Boundary-layer behavior on continuous solid surface on a continuous flat surface-I, The boundary layer on a continuous flat surface", AICHE J., (1961a), pp. 26-28.

[2] Sakiadis. B. C, "Boundary-layer behavior on continuous solid surface on a continuous flat surface-II, The boundary layer on a continuous flat surface", AICHE J, (1961b), pp. 221-225.

[3] Rajgopal K. R., T. Y. Na and A. S. Gupta, Flow of a viscoelastic fluid over a stretching sheet. Rheol. Acta, (1984.) pp. 213-215.

[4] Dandapat, B. S. and A. S. Gupta, "Flow and heat transfer in a viscoelastic fluid over a stretching sheet", Int. J. Non-Linear Mech., (1989) pp. 215-219.

[5] Gupta P. S., Gupta A. S., "Heat and Mass Transfer on a Stretching Sheet with Suction or Blowing", Can. J. Chem. Eng., (1977), pp. 744-746.

[6] Afzal N., Varshney I. S., "The Cooling of a Low Heat Resistance Stretching Sheet Moving through a Fluid", Warme Stoffubertrag, (1980), pp. 289-299.

[7] Banks W. H. H., "Similarity Solutions of the Boundary Layer Equations for a Stretching Wall”, J. Mec. Theor. Appl., (1983), pp. $375-392$.

[8] Grubka L. J., Bobba K. M., "Heat Transfer Characteristics of a Continuous Stretching Surface with Variable Temperature", ASME J. Heat Transfer, (1985), pp. 248-250.

[9] Chen C. K., Char M. I., "Heat Transfer of a Continuous Stretching Surface with Suction or Blowing”, J. Math. Anal. Appl., (1988), pp. 568-580.

[10] M. R. Haque., M. M. Alim, M. M. Ali, R. Karim., "Effects of viscous dissipation on natural convective flow over a sphere with temperature dependent thermal conductivity in presence of heat generation". Elsever (2015) pp. 215-224.

[11] Takhar, H. S., R. S. R. Glora and V. M. Soundalgekar, "Radiation effects on MHD free convection flow of radiating fluid past a semi-infinite vertical plate", Int. J. Num. Methods Heat Fluid Flow, (1996) pp. 77-83.

[12] Chamkha, A. J., H. S. Takhar and V. M. Soundalgekar, "Radiation effect on free convection flow past a semi-Infinite vertical plate with mass transfer. Chem. Eng. J., (2001) pp. 335-342.

[13] Raptis, A. 1nd C. Perdikis, "Radiation and free convection flow past a moving plate". App. Mech. Eng., (1999) pp. 817821.

[14] Kishan Naikoti, Shashidar Reddy Borra, "Quasi-linearization Approach to MHD Effects on Boundary Layer Flow of Power-Law Fluids Past A Semi Infinite Flat Plate with Thermal Dispersion", Int. J. of Non-Linear Science, Vol. 11, (2011), pp. 301-311.

[15] Mansour M. A. and Gorla R. S. R., "Mixed convectionradiation interaction in power- law fluids along a nonisothermal wedge embedded in a porous medium", Transport in Porous Media, (1998), pp. 113-124.

[16] Raptis A., "Flow of a micro polar fluid past a continuously moving plate by the presence of radiation", Int. J. Heat Mass Transfer, (1998), pp. 2865-2866.

[17] Sajid M. and Hayat T., "Influence of thermal radiation on the boundary layer flow due to an exponentially stretching sheet", Int. J. Heat Mass Transfer, Vol. 35, (2008), pp. 347-356.

[18] Sahoo B., Poncet S., "Flow an heat transfer of a third grade fluid past an exponentially stretching sheet with partial slip boundary condition", Int. J. Heat Mass Transfer, (2011), pp. 5010-5050.

[19] Kolar, A. K. and Sastri, V. M., "Free Convective Transpiration over a Vertical Plate"a Numerical Study", $J$. Heat and Mass Transfer, (1988), pp. 327-336.

[20] Camargo R., Luna E. and Trevino C., "Numerical Study of the Natural Convective Cooling of a Vertical Plate", J. Heat and Mass Transfer, (1996), pp. 89-95.

[21] M. A. Samad, M. M. Rahaman, M. A. Rahaman and M. Mohebujjaman, "Numerical Study of MHD Forced Convective Flow of a Micro polar Fluid past a non-linear Stretching Sheet with Variable Viscosity" Dhaka Univ J. Sci. (2009) 57 (2) pp. 243-248.

[22] M. M. Alim, M. A. Alim and M. K. Chowdhury, "Effect of pressure stress work and viscous dissipation in natural convection flow along a vertical plate with heat conduction" $J$. Naval and Marine Eng. 3. (2006) pp. 69-76. 
[23] K. C. Saha, M. A. Samad and M. R. Hossain, "Effect of viscous dissipation on MHD Free Convection flow Heat and Mass Transfer of Non-Newtonian Fluids along a Continuously moving Stretching Sheet" Research J. of App. Sciences, Eng. And Tech., (2015), pp. 1058-1073.
[24] Fahad B. Mostafa, M. A. Samad and M. R. Hossain. "Combined Effect of Viscous Dissipation and Radiation on Unsteady Free Convective Non-Newtonian Fluid along a Continuously Moving Vertically Stretched Surface with NoSlip Phenomena" American Journal of Computational and Applied Mathematics 20177 (3) pp. 71-79. 